\title{
Preliminary evidence for the occurrence of $\beta$-tubulin isotype 3 polymorphisms in Fasciola hepatica isolates in cattle and sheep in Turkey
}

\author{
S. SADET CANAKOGLU', S. SIMSEK ${ }^{2 *}$, I. BALKAYA ${ }^{3}$, S. GUNYAKTI KILINC ${ }^{2}$ \\ ${ }^{1}$ Department of Animal Sciences, Directorate of Provincial Food Agriculture and Livestock, Kayseri, Turkey; \\ ${ }^{2 \star}$ Department of Parasitology, Faculty of Veterinary Medicine, University of Firat, 23119, Elazig, Turkey, E-mail: ssimsek@firat.edu.tr, \\ ${ }^{3}$ Department of Parasitology, Faculty of Veterinary Medicine, University of Ataturk, Erzurum, Turkey
}

Article info

Received August 8, 2018

Accepted January 24, 2019

\begin{abstract}
Summary
Fasciolosis caused by Fasciola hepatica is a common parasitic disease of livestock especially sheep and cattle. In this study molecular characterization of $\beta$-tubulin isotype 3 gene in Fasciola hepatica isolates from cattle and sheep in Turkey was carried out. For this purpose a total of 80 adult Fasciola hepatica isolates were collected from 20 sheep and 20 cattle in Kayseri and Erzurum provinces. PCR-RFLP was performed on $\beta$-tubulin isotype 3 gene and Mboll revealed two fragments of approximately 350 bp and 390 bp, whereas Hphl enzyme yielded 210, 340 and 540 bp bands, Hindll yielded 380 and 450 bp bands in all samples. A total of 80 isolates were tested by SSCP and all of them presented the same band profiles. Six samples (4 sheep and 2 cattle) were randomly selected and DNA sequence of a $935 \mathrm{bp}$ coding fragment of $\beta$-tubulin isotype 3 was performed. Sheep samples were more polymorphic than the cattle. This $\beta$-tubulin isotype 3 gene polymorphism of F.hepatica isolates from sheep and cattle of two distinct geographical areas of Turkey have been investigated for the first time.
\end{abstract}

Keywords: Fasciola hepatica; $\beta$-tubulin 3; Polymorphism; Sheep; Cattle; Turkey

\section{Introduction}

The liver fluke, Fasciola hepatica, is a worldwide distributed trematode parasite of great veterinary importance, which causes significant economic losses (feed conversion efficiency, poor carcass conformation, malnutrition, decreased fertility and milk yield) in livestock (Khoramian et al., 2014). It is a food-borne trematode zoonosis and is classified as neglected tropical disease $\mathrm{WHO}$, 2015). Fasciolosis is an asymptomatic infection in cattle and causes more serious pathological implications in sheep. Acute fasciolosis in sheep occurs seasonally and manifests itself with a relatively swollen and painful abdomen; and sudden death occurs within $2-6$ weeks after infection. Advanced chronic infection is fatal in sheep, this rate is less in cattle (Mas-Coma et al., 2005). Survival is longer in cases of significant liver damage (7 - 10 weeks) in subacute disease, however, death can occur due to hemorrhage and anemia. Although chronic fasciolosis can be seen during all seasons of the year, it occurs primarily in autumn and winter. Anemia, unthriftiness, submandibular edema and decreased milk production are the most important symptoms. The benzimidazole derivative triclabendazole is a highly specific drug for the treatment of fasciolosis (Fairweather \& Boray, 1999). Microtubules are highly conserved among species, the polymers of $\alpha$ and $\beta$-tubulin, in heterodimer form. The Fasciola hepatica genome codes for at least five $\alpha$ and six $\beta$-tubulin isotypes (Ryan et al., 2008). $\beta$-tubulin proteins have been characterised from a variety of helminth species. To date, however, there is no data about the polymorphism in the $\beta$-tubulin gene from isolates in Turkey.

In the present study we investigated the possible polymorphism in the $935 \mathrm{bp}$ fragment of $\beta$-tubulin isotype 3 gene of $F$. hepatica

\footnotetext{
$\overline{\text { * }- \text { corresponding author }}$
} 


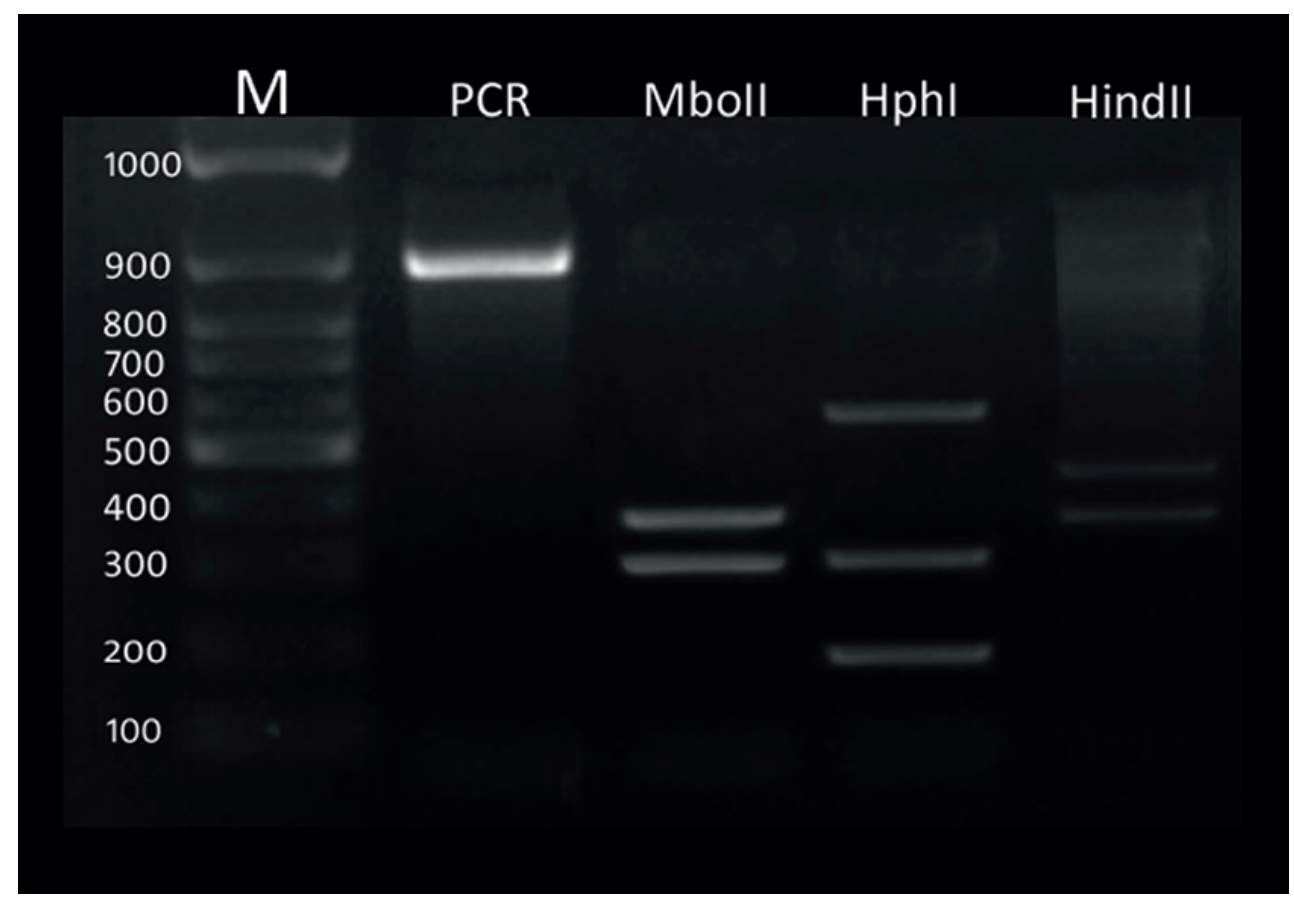

Fig. 1. PCR and PCR-RFLP results of Fasciola hepatica $\beta$-tubulin gene. M: Marker (100 bp); PCR: $\beta$-tubulin gene (935 bp);

Mboll: Restriction with Mboll (350 and 390 bp); Hphl: Restriction with Hphl (210, 340 and 540 bp); Hindl: Restriction with Hindl (380 and 450 bp).

which has been collected from sheep and cattle isolates from different geographical areas of Turkey.

\section{Materials and Methods}

\section{Sample Collection}

The study defines an isolate as a single adult $F$. hepatica from each separate liver. A total of 80 isolates from livestock (sheep $n=20$, cattle $n=20$ ) originating from Erzurum and Kayseri provinces were collected over a period of 2 years (January 2014-December 2015) during random visits to licensed slaughterhouses in Turkey. The isolates were preserved in $70 \%$ ethanol and were transferred to the laboratory for genomic DNA isolation.

\section{Genomic DNA Isolation}

Total genomic DNA (gDNA) was isolated from the adult parasite tissue using the GeneAll${ }^{\circledR}$ Tissue Kit (Korea) according to the manufacturer's instructions. Prior to gDNA isolation, the anterior part of each adult parasite was dissected and ethanol residue was removed by at least five times repeated wash in $600 \mu \mathrm{l} 1 \mathrm{M}$ PBS (pH=7,4). gDNA quality was evaluated by optical density ratio (260/280 nm), using a NanoDrop 8000 Spectrophotometer (Thermo Scientific). gDNA isolated samples were used for further PCR and sequence analysis.

\section{Polymerase Chain Reaction (PCR)}

A fragment (935 bp) of $\beta$-tubulin isotype 3 gene was amplified using the primers $\beta$-tub295f (5'-AAYAAYTGGGCYAARGGNCAY-
TA-3') and $\beta$-tub1230r (5'-TCRGTRAAYTCCATYTCRTCCAT-3') previously reported (Ryan et al., 2008). We used the following conditions: initial denaturation step of $10 \mathrm{~min}$ at $95^{\circ} \mathrm{C}$ and 40 cycles of $1 \mathrm{~min}$ at $94^{\circ} \mathrm{C}$ (denaturation), $1 \mathrm{~min}$ at $56^{\circ} \mathrm{C}$ (primer annealing), $1 \mathrm{~min}$ at $72^{\circ} \mathrm{C}$ (extension) followed by a final extension step of 10 min at $72^{\circ} \mathrm{C}$. Amplicons were electrophoretically visualized on an ethidium bromide stained $1.4 \%$ agarose gel under UV.

Restriction Fragment Lenght Polymorphism (PCR-RFLP)

The restriction enzymes used for this procedure were determined using previously published sequences (HM535826, HM535800 and HM535806) in PubMed. NEBCutter V2.0 program was used to determine which enzymes cut the sequence and Mboll $(5 \mathrm{U} /$

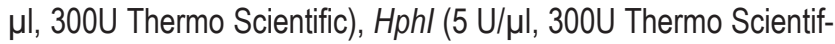
ic) and HindlI ( $5 \mathrm{U} / \mu \mathrm{l}, 300 \mathrm{U}$ Thermo Scientific) were used in this

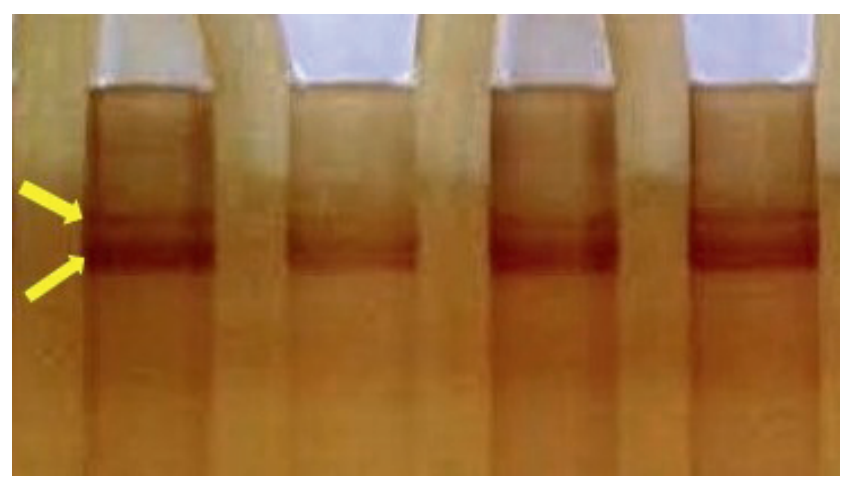

Fig. 2. SSCP band profiles of some selected samples. 
study. PCR products were digested during 3 hours with restriction enzymes at $37^{\circ} \mathrm{C}$ using buffers recommended by the manufacturer (Thermo Scientific) in a final 18,7 $\mu$ l volume reaction mix, containing $10 \mu \mathrm{l}$ of PCR product, $1 \mu$ from each enzyme (Mboll, $\mathrm{Hphl}$ and HindII), $2 \mu$ restriction buffer, $0.2 \mu \mathrm{l}$ BSA and $5.5 \mu$ distilled water. The restriction fragments were separated on $3 \%$ agarose gel, stained with ethidium bromide and photographed (Vilber Lourmat Quantum-ST5-1100/26MX).

Single Stranded Conformation Polymorphism (SSCP)

The method was performed according to Simsek et al. (2012).

Eight microliters of each PCR product were mixed with $12 \mu$ of

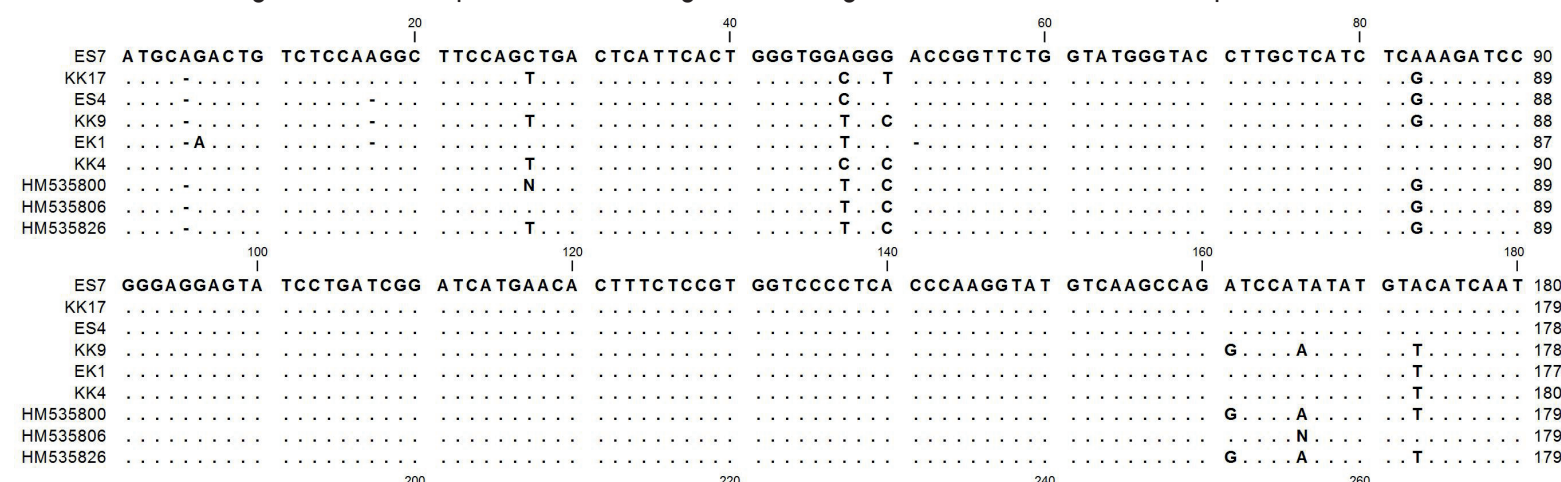

\section{0}

${ }_{12}^{220}$

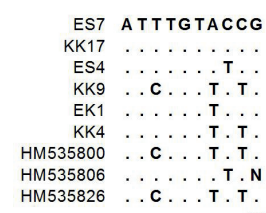

280

300

${ }^{240}$

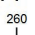

160

GGA TGAGACG 270

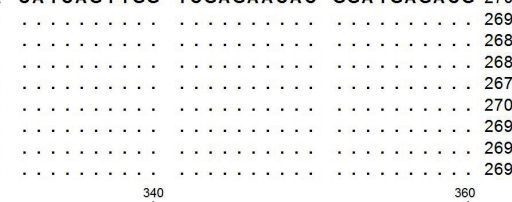

\section{0}

340

360
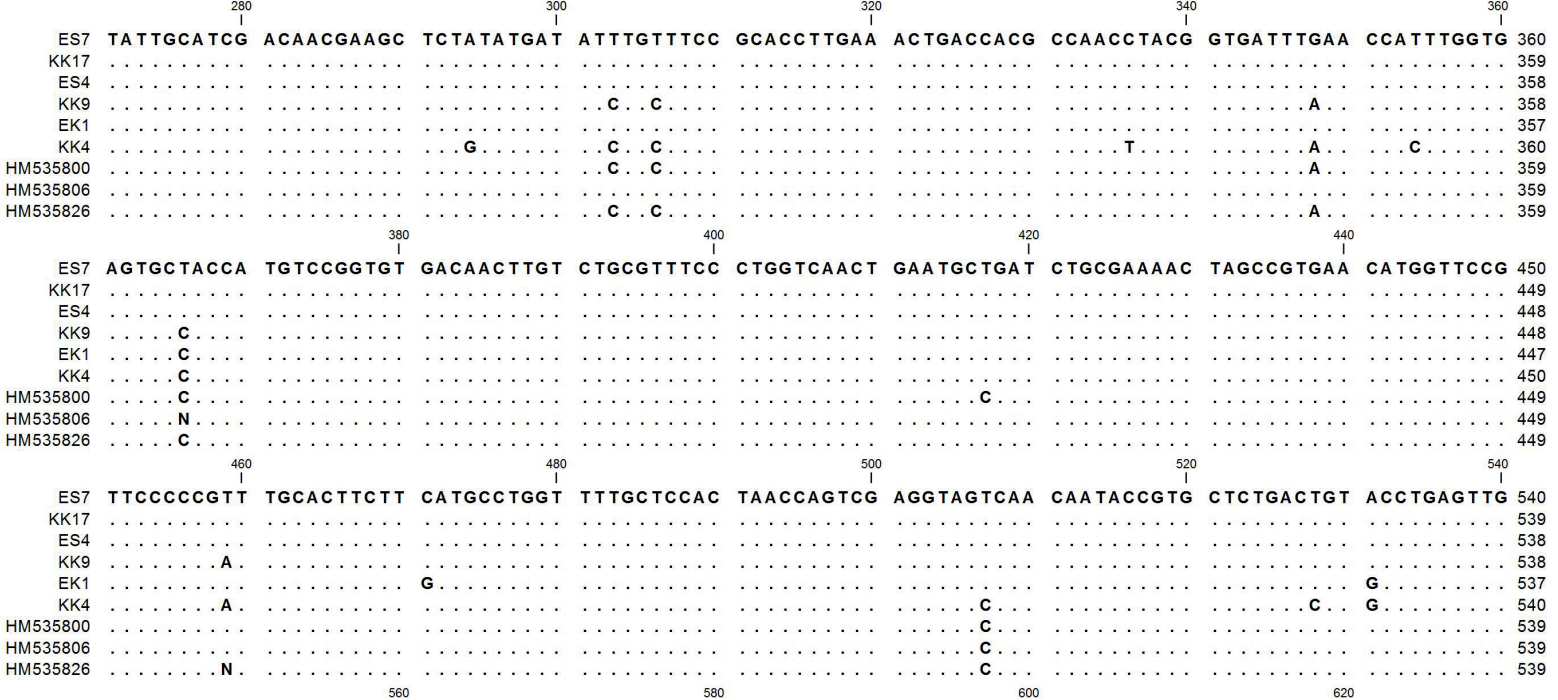

560
1

${ }^{580}$

${ }^{600}$

\section{$\stackrel{620}{12}$}

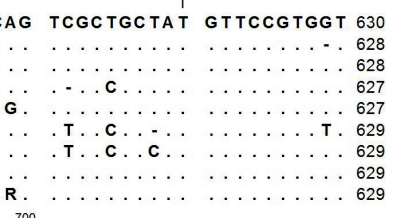

680

700

${ }_{1}^{640}$

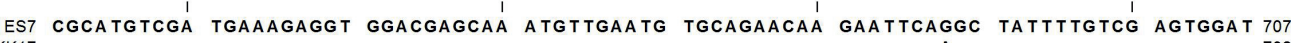

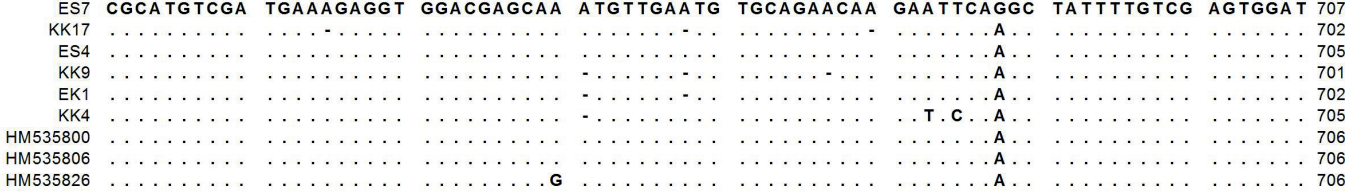

Fig. 3. Nucleotide sequence alignment of samples analyzed in this study using with the reference sequences (HM535800, HM535806 and HM535826). 


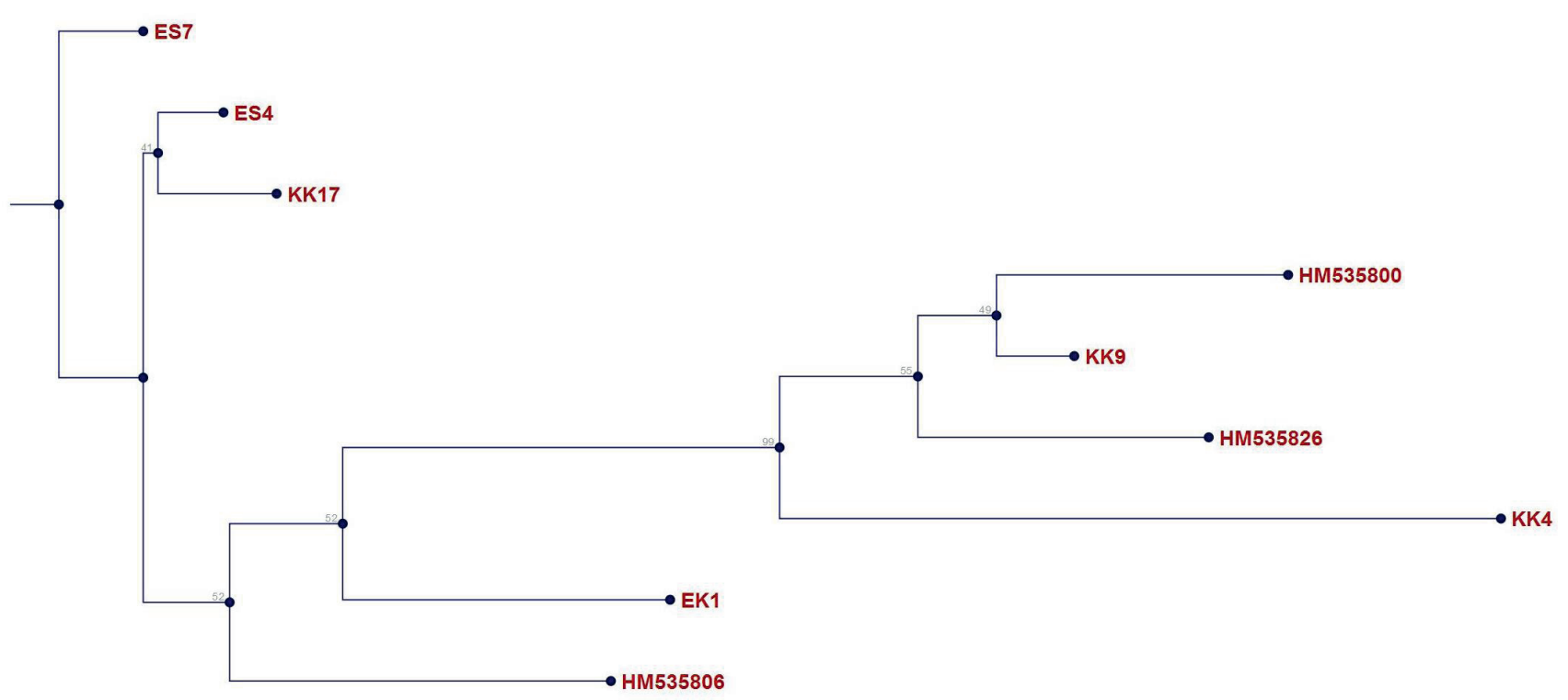

Fig. 4. Phylogenetic tree view of the aligned nucleotide sequences using with the reference sequences (HM535800, HM535806 and HM535826).

denaturing buffer $(10 \mathrm{mM} \mathrm{NaOH}, 95 \%$ formamide, $0.05 \%$ bromophenol blue and $0.05 \%$ xylene cyanole). Following the denaturation at $95^{\circ} \mathrm{C}$ for $10 \mathrm{~min}$ and subsequent snap-cooling on a freeze block $\left(-20^{\circ} \mathrm{C}\right), 10 \mu$ of individual samples were loaded into the gel. The electrophoresis was carried out in $12 \%$ acrylamide-bisacrylamide (49:1) non-denaturing gels containing $10 \%$ glycerol, at $200 \mathrm{~V}$ constant current during $3 \mathrm{~h}$ at room temperature. The band profiles were displayed by silver staining.

\section{DNA Sequence Analysis}

The $F$. hepatica partial $\beta$-tubulin gene sequences were obtained automatically. Nucleotide sequence analysis was undertaken by BLAST algorithms and databases from the NCBI (http://www. ncbi.nlm.nih.gov). The following accession numbers were given to sequences: KU523368, KU523369, KU523370, KU523371, KU523372 and KU523373.

\section{Ethical Approval and/or Informed Consent}

For this study formal consent is not required (Firat University, Local Ethics Committee of Animal Experiments, Decision no: 2014/73).

\section{Results}

A $935 \mathrm{bp}$ fragment of $\beta$-tubulin isotype 3 gene was amplified through PCR in $80 \mathrm{~F}$. hepatica isolates (Fig. 1). The molecular characterization of F.hepatica was carried out on the basis of PCR-RFLP and SSCP analysis of $\beta$-tubulin isotype 3 gene and sequence analysis as well. Three restriction enzymes (Mboll, $H p h l$ and HindII) were used to differentiate the $\beta$-tubulin isotype
3 gene of adult flukes. Different band patterns were observed in PCR-RFLP after enzyme digestion. The PCR-RFLP profile obtained from Mboll revealed two fragments of approximately $350 \mathrm{bp}$ and $390 \mathrm{bp}$ (Fig. 1), whereas Hphl enzyme yielded 210, 340 and 540 bp bands (Fig. 1), and Hindll yielded 380 and 450 bp bands (Fig. 1) in all samples. A total of 80 isolates were tested by SSCP and all of them presented the same band profile (Fig. 2). Six samples ( $n=4$ from sheep in Kayseri, $n=2$ from cattle in Erzurum) were randomly selected and sequenced. Four of those samples were isolated from sheep in Kayseri (KK4, Accession no: KU523371; KK9, Accession no: KU523372; KK17, Accession no: KU523373) and Erzurum (EK1, Accession no:KU523368) while the remaining two samples were isolated from cattle in Erzurum (ES4, Accession no: KU523369 and ES7 Accession no: KU523370). Multiple sequence alignment was performed including the previously published sequences (HM535800, HM535806 and HM535826) used for alignment and the results are shown in Fig. 3. According to alignment results, much more polymorphic sites were seen in sheep isolates (KK4, KK9 ve KK17) than the cattle. It has been illustrated in a genetic tree as well (Fig. 4). Amino acid comparisons of the samples were performed and mutations at different ratios at the sequence were observed (Fig. 5). The $\beta$-tubulin 3 gene sequences described in the current study were compared to those described previously (HM535800, HM535806 and HM535826). Thyrosin amino acid was detected in all sequenced and control sequences in $200^{\text {th }}$ position.

\section{Discussion}

Molecular studies on the genetic diversity of Fasciola species using 


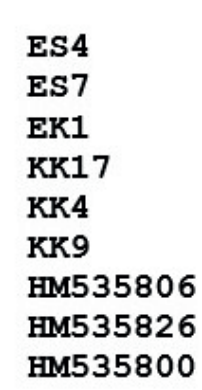

ES4
ES7
EK1
KK17
KK4
KK9
HM535806
HM535826
HM535800

\section{ES4}

ES7

EK1

KK17

KK4

KK9

HM535806

HM535826

HM535800

VSDTVVEPYNATLSVHQLVENTDETYCIDNEAL
VSDTVVEPYNATLSVHQLVENTDETYCIDNEAL
VSDTVVEPYNATLSVHQLVENTDETYCIDNEAL
VSDTVVEPYNATLSVHQLVENTDETYCIDNEAL
VSDTVVEPYNATLSVHQLVENTDETYCIDNEAL
VSDTVVEPYNATLSVHQLVENTDETYCIDNEAL
VSDTVVEPYNATLSVHQLVENTDETYCIDNEAL
VSDTVVEPYNATLSVHQLVENDETYCIDNEAL
VSDTVVEPYNATLSVHQLVENTDETYCIDNEAL

200

SGVTTCLRFPGQLNADIRKLAVNMVPFRRHFMPGAPITSRGSOYRATVPETTOQMF

SGVTTCLRFPGQLNADLRKLAVNMVPFPRLHF FMPGFAPLTSRGSQQYRALTVPELTQQMF SGVTTCLRFPGQLNADLRKLAVNMVPFPRLHFLMPGFAPLTSRGSQQYRALTVPELTQQMF SGVTTCLRFPGQLNADLRKLAVNMVPFPRLHFFMPGFAPLTSRGSQQYRALTVPELTQQMF SGVTTCLRFPGQLNADLRKLAVNMVPFPRLHF FMPGFAPLTSRGSQQYRALTVPELTQQMF SGVTTCLRFPGQLNADLRKLAVNMVPFPRLHF FMPGFAPLTSRGSQQYRALTVPELTQQMF SGVTTCLRFPGQLNADLRKLAVNMVPFPRLHFFMPGFAPLTSRGSQQYRALTVPELTQQMX SGVTTCLRFPGQLNADLRKLAVNMVPFPRLHFFMPGFAPLTSRGSQQYRALTVPELTQQMF SGVTTCLRFPGQLNADLRKLAVNMVPFPRLHF FMPGFAPLTSRGSQQYRALTVPELTQQMF

DAKNMMAACDPRHGRYLTVA DAKNMMAACDPRHGRYLTVA DAKNMMAACDPRHGRYLTVA DAKNMMAACDPRHGRYLTVA DAKNMMAACDPRHGRYLTVA DAKNMMAACDPRHGRYLTVP

XAKNMMAACDPRHGRYLTVA XAKNMMAACDPRHGRYLTVA DAKNMMAACDPRHGRYLTVA
225

225

225

225

225

225

225

225

225

286

286

286

286

286

286

286

286

286

306

306

306

306

306

306

306

306

306

Fig. 5. Alignment of the partial $\beta$-tubulin isotype 3 amino acid sequence with other relevant sequences (HM535800, HM535806 and HM535826). Alignment has been started from 99. position of the reference sequences. Amino acid residues that are conserved in at least 2 proteins are indicated in white back ground. Rectangle on the alignment indicate Tyr amino acid in the $200^{\text {th }}$ position.

mt-DNA have confirmed genetically varied populations (Elliot et al., 2014). Level of genetic diversity of $F$. hepatica suggests that it may have the potential to adapt to selection pressure within the environment with clonal reproduction in snails allowing rapid dispersal of resistant populations (Prugnolle et al., 2005). Microtubules are the major promoters of cytoskeleton and are widespread in all eukaryotic cells. They accompany some functions including cell division and intracellular transport mechanisms (Nogales et al., 1998). It has been previously established that the adult flukes express at least six tubulin isotypes designated as $F$. hepatica $\beta$-tub1 to $\beta$-tub6 (Ryan et al., 2008). The gene coding $\beta$-tub isotype 3 was chosen in the current study. The total length of the gene is $1335 \mathrm{bp}$. Selected primers were used for amplification of region $935 \mathrm{bp}$ in length. This is a region encoding 242 amino acids of the protein sequence.

Cwiklinski et al. (2015) highlighted tubulins exhibit the highest log fold-changes in expression throughout $F$. hepatica development. They identified the full complement of five $\alpha$-tubulin and six $\beta$-tubulin isotypes and found duplication of $\beta$-tubulin isotype 3 . We investigated levels of polymorphism among individual $F$. hepatica isolates collected from sheep and cattle by partial sequencing of the $\beta$-tubulin isotype 3 . It has been detected more nucleotide polymorphism in sheep isolates than cattle. This may be due to the more common prevalence of sheep fasciolosis than the cattle in Turkey.

In our study, DNA sequences of 6 randomly selected samples were obtained from samples amplified by $\beta$-tubulin isotype 3 gene PCR of $80 \mathrm{~F}$. hepatica isolates from Erzurum and Kayseri provinces. Sequence analysis resulted in amino acid comparisons of the samples, we observed the Thyrosin $(Y)$ in the $200^{\text {th }}$ position in all sequenced samples. Ryan et al. (2008) also identified Tyrosine at position 200 of the $\beta$-tubulin isotypes $1-3$, Phenylalanine $(F)$ in isotype 4 and 6 in two samples and Leucine in isotype 5 in one.

Teofanova et al. (2011) examined mutation and polymorphism in the $\beta$-tubulin 3 gene in $204 F$. hepatica isolates obtained from Greece $(n=143)$, Poland $(n=48)$ and Bulgaria $(n=13)$ using sequence analysis. As a result, two major lineages for the $28 \mathrm{~S}$ rDNA gene based on the highly polymorphic $105^{\text {th }}$ nucleotide position 
have been found. The basic lineages were observed within Greek, Bulgarian, and Polish F. hepatica populations but the distribution of additional haplotypes differed between the populations from the three countries. For the $\beta$-tubulin isotype 3 gene multiple polymorphic sites were revealed but no explicit clades. The SNPs were spread unequally in all studied geographical regions with an evident distinction between the Greek and Polish specimens. In our study, a few polymorphic points were identified in the sequenced sheep and cattle samples. These results indicate that phylogenetic analysis based on partial sequences of $\beta$-tubulin isotype 3 belonging to $F$. hepatica may support the polymorphism and allow understanding of the variation on the $\beta$-tubulin gene. Our findings suggest that the genetic diversity of $F$. hepatica $\beta$-tubulin isotype 3 of sheep and cattle isolates still continues. However for the better understanding of the sequence variability it needs to more lengths partial sequences.

In conclusion, this is the first report of a $\beta$-tubulin isotype 3 characterization in Turkey. The results of the current study contributed to understanding of the genetic structure and heterogeneity of $F$. hepatica $\beta$-tubulin isotype 3 in Turkey. However it needs further studies by using more sequenced samples.

\section{Conflict of Interest}

The authors fully declare that there is no financial or other potential conflict of interest.

\section{Acknowledgements}

This study has been supported by a grant from Firat University Scientific Research Projects Unit (Project No: VF.14.05). We also would like to thank to Dr. Alan Trudgett for the kind helps. The authors thank to Naunain Mehmood for the language edition.

\section{References}

Cwiklinski, K., Dalton, J.P., Dufresne, P.J., La Course, J., Williams D.J., Hodgkinson, J., Paterson, S. (2015): The Fasciola hepatica genome: gene duplication and polymorphism reveals adaptation to the host environment and the capacity for rapid evolution. Genome Biol., 3(16):71. doi: 10.1186/s13059-015-0632-2

Elliott, T., Muller, A., Brockwell, Y., Murphy, N., Grillo, V., Toet, H.M., Anderson, G., Sangster, N., Spithill, T.W. (2014): Evidence for high genetic diversity of NAD1 and COX1 mitochondrial haplotypes among triclabendazole resistant and susceptible populations and field isolates of Fasciola hepatica (liver fluke) in Australia. Vet. Parasitol., 200(1-2): 90-6. DOI: 10.1016/j.vetpar.2013.11.019

FAIRWEATHER, I., BorAY, J.C. (1999): Fasciolicides: efficacy, actions, resistance and its management. Vet. J., 158: 81 - 112

Khoramian, H., Arbabi, M., Osqol, M.M., Delavari, M., Hooshyar, H., Asgari, M. (2014): Prevalence of ruminants fascioliasis and their economic effects in Kashan, center of Iran. Asian Pacific J. Trop. Biomed., 4: 918 - 922. DOI: 10.12980/APJTB.4.2014APJTB-2014-0157

Mas-Coma, S., Bargues, M.D., Valero, M.A. (2005): Fascioliasis and other plant-borne trematode zoonoses. Int. J. Parasitol., 35: 1255 - 78. DOI: 10.1016/j.ijpara.2005.07.010

Nogales, E., Wolf, S.G., Downing, K.H. (1998): Structure of the alpha beta tubulin dimer by electron crystallography. Nature, 391: $199-203$

Prugnolle, F., Liu, H., De Meeus, T., Balloux, F. (2005): Population genetics of complex life-cycle parasites: an illustration with trematodes. Int. J. Parasitol. 35: 255 - 263

Ryan, L.A., Hoey, E., Trudgett, A., Fairweather, I., Fuchs, M., Robinson, M.W., Chambers, E., Timson, D., Ryan, E., Fetwell, T., Ivens, A., Bentley, G., Johnston, D. (2008): Fasciola hepatica expresses multiple a- and b-tubulin isotypes. Mol. Biochem. Parasitol., 159: 73 - 78. DOI: 10.1016/j.molbiopara.2008.02.001

Simsek, S., Ozcetin, C., Balkaya, I. (2012): Detection of polymorphism in AgB1 gene from sheep, cattle and human isolates of echinococcus granulosus by SSCP. Vet. Parasitol., 184: 352 - 355. DOI: 10.1016/j.vetpar.2011.09.002

Teofanova, D., Kantzoura, V., Walker, S., Radoslavov, G., Hristov, P., Theodoropoulos, G., Bankov, I., Trudgett, A. (2011): Genetic diversity of liver flukes (Fasciola hepatica) from Eastern Europe. Infect. Gen. Evol., 11: 109 - 115. DOI: 10.1016/j.meegid.2010.10.002 WHO (2015): Neglected tropical diseases list. Internet Access: http://www.who.int/neglected_diseases/diseases/en/ 